\title{
Molecular characterization and antimicrobial susceptibility of Staphylococcus aureus isolated from children with acute otitis media in Liuzhou, China
}

Yan Ling Ding ${ }^{1 \dagger}$, Jinjian $\mathrm{Fu}^{1 \dagger}$, Jichang $\mathrm{Chen}^{2 \dagger}$, Sheng $\mathrm{Fu} \mathrm{Mo}{ }^{1 \dagger}$, Shaolin $\mathrm{Xu}^{1}$, Nan $\mathrm{Lin}^{3}$, Peixu Qin ${ }^{1}$ and Eric McGrath ${ }^{4,5^{*}}$ (D)

\begin{abstract}
Background: There have been few studies focused on the prevalence, bacterial etiology, antibiotic resistance, and genetic background of Staphylococcus aureus (S. aureus) in children with acute otitis media (AOM) in China.

Methods: A retrospective study was conducted in Liuzhou Maternity and Child Healthcare Hospital. Patients younger than 18 years diagnosed with AOM were enrolled in the study. Middle ear fluid specimens were collected and cultured for bacterial pathogens. The antibiotic susceptibility, virulence genes, macrolide resistant genes and sequence types of $S$. aureus were identified.
\end{abstract}

Results: From January 1, 2013 to December 31, 2015, a total of 228 cases of AOM were identified. Pathogenic bacteria were positive in 181 (79.4\%) of 228 specimens. Streptococcus pneumoniae was the most common bacteria (36.4\%), followed by S. aureus (16.2\%). Among the 37 S. aureus isolates, 12 (23.5\%) were methicillin-resistant S. aureus (MRSA), and 25 (77.5\%) were methicillin-susceptible S. aureus (MSSA). A total of 23 isolates (62.2\%) were resistant to erythromycin, $40.5 \%$ of isolates were resistant to clindamycin, and $37.8 \%$ isolates were resistant to tetracycline. Twenty-three isolates were multi-drug resistant (MDR) S. aureus. Eighteen isolates carried the pvl gene. Up to 22 (59. 4\%) isolates expressed ermA gene, 8 (21.6\%) isolates expressed both ermA and ermC genes, and only $8.1 \%$ expressed ermB. Among all S.aureus isolates, 7 sequence types (STs) were identified by multilocus sequence typing (MLST). The most common ST was ST59 (16/37, 43.2\%), followed by ST45 (7/37, 18.9\%) and ST30 (7/37, 18.9\%). The predominant MSSA isolates were ST59-t437-MSSA (5/25, 20.0\%), the prevailing MRSA isolates were Taiwan related strains ST59-SCCmec-IVaN (5/12, 41.6\%).

Conclusions: S. aureus was the second most common cause for AOM in children in Liuzhou. Most of the S. aureus was MDR which carried a high proportion of ermA and ermC gene. CA-MRSA (ST59-SCCmec-IVN-t437) is circulating in children with AOM. These findings support continued surveillance of S. aureus infections in children with AOM in both communities and hospitals.

Keywords: Staphylococcus aureus, Acute otitis media, Antibiotic resistance, Genetic background, Pediatrics

\footnotetext{
* Correspondence: emcgrath@med.wayne.edu

†Yan Ling Ding, Jinjian Fu, Jichang Chen and Sheng Fu Mo contributed equally to this work.

${ }^{4}$ Children's Hospital of Michigan, Detroit, MI, USA

${ }^{5}$ Department of Pediatrics, Wayne State University School of Medicine, 3901

Beaubien Blvd, Detroit, MI 48201, USA

Full list of author information is available at the end of the article
}

(c) The Author(s). 2018 Open Access This article is distributed under the terms of the Creative Commons Attribution 4.0 International License (http://creativecommons.org/licenses/by/4.0/), which permits unrestricted use, distribution, and reproduction in any medium, provided you give appropriate credit to the original author(s) and the source, provide a link to the Creative Commons license, and indicate if changes were made. The Creative Commons Public Domain Dedication waiver (http://creativecommons.org/publicdomain/zero/1.0/) applies to the data made available in this article, unless otherwise stated. 


\section{Background}

Acute otitis media (AOM) is a common pediatric bacterial infection affecting approximately $80 \%$ of children prior to the age of 3 years [1]. The incidence of AOM in Chinese children was reported to be between 57.2 and $69.4 \%$ in children age $0-2$ years [2]. AOM is the primary reason for the prescription of antibiotics in children [3]. The extensive use of antibiotics has been a public health problem in China [4]. Understanding the epidemiology and the etiology of AOM is important for the clinical selection of empiric treatment.

It was reported that the incidence of pediatric AOM and the causative pathogens varied among different regions and geographic settings. Although Streptococcus pneumoniae (S. pneumoniae), Haemophilus influenzae (H. influenzae), and Moraxella catarrhalis (M. catarrhalis) are the three leading causes of AOM in children [5], it was noted that the primary bacteria responsible for AOM in Chinese children are S. pneumoniae, Staphylococcus aureus (S. aureus) and H. influenzae [2]. S. aureus was considered a major pathogen that led to infection and hospitalization in pediatric patients, including healthy subjects in the community in past decades [6,7]. Although methicillin-resistant Staphylococcus aureus (MRSA) causing pediatric infections such as skin and soft tissue infections, pneumonia, and blood stream infections are well documented, detailed studies of the contribution of S.aureus (both MRSA and methicillin-sensitive Staphylococcus aureus, MSSA) to $\mathrm{AOM}$ are limited. There have been few studies focused on the epidemiology of pediatric AOM in China. The aim of this study was to both evaluate the bacterial etiology of AOM and the antibiotic resistance patterns of $S$. aureus in pediatric AOM disease and investigate the molecular features and genetic background of $S$. aureus AOM in children from western China.

\section{Methods}

\section{Patients and sample collections}

This retrospective study was conducted between January 1, 2013 and December 31, 2015 in the otolaryngology clinic of Liuzhou Maternity and Child Healthcare Hospital. Patients younger than 18 years were enrolled in the study. The diagnostic criteria for AOM was based on the International Classification of Diseases, ninth version, Clinical Modification (ICD-9-CM) code 3810, 3820, or 3829 [3]. Any child diagnosed with chronic otitis media, or who had prior history of tympanostomy tube insertion, cholesteatomas, or otitis externa were excluded. Spontaneous ear pus drainage from the deep ear canal was swabbed by otolaryngologists and then sent to the microbiology laboratory.

The specimens were immediately plated on Columbia agar containing 5\% sheep blood, on chocolate agar and on MacConkey agar. All agars were placed in $35-37^{\circ} \mathrm{C}$, $5-10 \% \mathrm{CO}_{2}$ incubated for $24 \mathrm{~h}$ to $48 \mathrm{~h}$. The suspected bacteria were identified using VITEK 2 compact automatic microbial analysis system (Biomérieux, Marcyl' Etoile, France).

\section{Antimicrobial susceptibility test}

Antimicrobial susceptibility test of $S$. aureus was performed using the Gram-positive cocci antibiotic cards (Biomérieux, Marcyl' Etoile, France). Minimum inhibitory concentrations (MICs) were proposed using in-house prepared panels according to Clinical and Laboratory Standards Institute (CLSI) guidelines [8]. Isolates not susceptible to at least 3 different antibiotic classes such as $\beta$-lactams, macrolides, and glycopeptides were defined as multidrug-resistant (MDR) S. aureus.

\section{Detection of the mecA, Panton-Valentine Leukocidin (pvl) and erythromycin-resistance genes}

The mecA and $l u k S-P V$ or $l u k F-P V$ genes (both of which encode for $p v l$ ) were detected as described previously [9]. The macrolide resistance genes $\operatorname{erm} A$, ermB and ermC were amplified by PCR methods for all erythromycin-resistance isolates [10].

\section{SCCmec typing}

The staphylococcal cassette chromosome mec (SCCmec) was distinguished by the updated multiplex PCR assay developed by Zhang $\mathrm{K}$ et al. [11].

\section{Multilocus sequence typing (MLST)}

MLST was performed by PCR amplification and sequencing of 7 housekeeping genes by using primers and protocols described previously [12]. DNA sequences were submitted to the MLST database website (www.mlst.net) for the generation of an allelic profile and sequence type (ST).

\section{Spa typing}

Spa typing was determined by using established method [13]. Sequences were submitted to the RIDOM web server (http://spaserver.ridom.de) for assignment of the spa type.

\section{Statistical analysis}

Data were analyzed using descriptive statistics and $x^{2}$ tests. The two-sided $p$-value for statistical significance was defined as $p<0.05$. All statistical analyses were conducted using SPSS version 20.0 (SPSS Inc. Chicago, Il, USA). 


\section{Results}

\section{Epidemiology and microbiology}

Two hundred and twenty-eight children age $0-15$ years were identified with AOM in the otolaryngology clinic during the study period. The median age was 24 months. Sixty-six percent of them were less than 2 years. The male-to-female ratio was 1:0.6. (Table 1). Pathogenic bacteria were positive in 181 (79.4\%) of 228 specimens, S. pneumoniae was the most common bacteria (36.4\%), followed by S. aureus (16.2\%), Pseudomonas aeruginosa (4.4\%) and H. influenzae (3.9\%) (Table 2).

Among the $37 \mathrm{~S}$. aureus isolates, 12 (23.5\%) were MRSA, and 25 (77.5\%) were MSSA. All isolates were susceptible to ciprofloxacin, rifampicin, linezolid and vancomycin. A total of 23 isolates (62.2\%) were resistant to erythromycin, and $37.8 \%$ isolates were resistant to tetracycline. The resistant rate to clindamycin was higher in the MSSA group than in the MRSA group ( $p$ $=0.040$ ) (Table 3). Twenty-three isolates were multi-drug resistant (MDR) S. aureus. In the MRSA group, the MDR rate was $83.3 \%$, while in the MSSA group, the MDR rate was $52.0 \%$. The most common MDR pattern was resistance to penicillin/erythromycin /clindamycin/tetracycline.

\section{Virulence and macrolide-resistance genes}

Eighteen $S$. aureus isolates carried the $p v l$ gene. The $p v l$ gene distribution varied between the MRSA and the MSSA groups, with 9 MRSA isolates (75.0\%) and 9 MSSA isolates (36.0\%) carring the $p v l$ gene, with MRSA isolates having a higher proportion than the MSSA group $\left(x^{2}=4.94, p=0.026\right)$. Up to $22(59.4 \%)$ isolates expressed the ermA gene, and 8 (21.6\%) isolates expressed both ermA and ermC genes, and only $8.1 \%$ expressed ermB. Eighty-three and $41 \%$ of MRSA isolates expressed ermA and erm $C$ genes, respectively, while only $12(32.4 \%)$ and $4(10.8 \%)$ of MSSA isolates expressed ermA and erm $C$ gene, which was significantly different $(p=0.016$, and 0.002 , respectively) (Table 4$)$.

Table 1 The demographic information of children with AOM

\begin{tabular}{|c|c|c|c|c|}
\hline \multirow[t]{2}{*}{ Characteristic } & \multicolumn{2}{|c|}{$\mathrm{AOM}$} & \multicolumn{2}{|c|}{ Staphylococcus aureus positive } \\
\hline & $\mathrm{N}$ & $\%$ & $\mathrm{~N}$ & $\%$ \\
\hline \multicolumn{5}{|l|}{ Gender } \\
\hline Male & 141 & 61.8 & 21 & 56.8 \\
\hline Female & 87 & 38.2 & 14 & 43.2 \\
\hline \multicolumn{5}{|l|}{ Age (years) } \\
\hline$<1$ & 106 & 46.5 & 17 & 45.9 \\
\hline $1-$ & 46 & 20.2 & 8 & 21.6 \\
\hline $2-$ & 49 & 21.5 & 7 & 18.9 \\
\hline$\geq 5$ & 27 & 11.8 & 5 & 13.5 \\
\hline
\end{tabular}

Table 2 Microbiology of middle ear fluid from children with acute otitis media

\begin{tabular}{ll}
\hline Pathogen & No. of strains (\%) \\
\hline No growth & $47(20.6)$ \\
Any growth & $181(79.4)$ \\
Streptococcus pneumoniae & $83(36.4)$ \\
Staphylococcus aureus & $37(16.2)$ \\
Haemophilus influenzae & $9(3.9)$ \\
Streptococcus pyogenes & $4(1.7)$ \\
Moraxella catarrhalis & $1(0.4)$ \\
Candida albicans & $5(2.2)$ \\
Fungus & $6(2.6)$ \\
Pseudomonas aeruginosa & $10(4.4)$ \\
Klebsiella pneumoniae & $4(1.7)$ \\
Escherichia coli & $3(1.3)$ \\
Proteus mirabilis & $2(0.8)$ \\
\hline
\end{tabular}

\section{Molecular typing}

Among the 12 MRSA isolates, 4 (33.3\%) belonged to SCCmec type IVa, 5 (41.6\%) belonged to SCCmec type IV, and $3(25.8 \%)$ belonged to SCCmec type V. Twelve Spa types were identified, t437 (13/37, 35.1\%) was the most common type, followed by t037 (6/37, 16.2\%), and t021 (4/37, 10.8\%). The $\mathrm{t} 437(8 / 12,75.0 \%)$ and $\mathrm{t} 437(5 /$ $25,20.0 \%)$ type was the most common Spa type in the MRSA and the MSSA groups, respectively.

Among all S. aureus isolates, 7 sequence types (STs) were identified by MLST. The most common ST was ST59 (16/37, 43.2\%), followed by ST45 (7/37, 18.9\%) and ST30 (7/37, 18.9\%) (Table 5). The predominant MSSA isolates were ST59-t437-MSSA (5/25, 20.0\%), the second predominant MSSA were southwest-pacific strains ST30-t037-MSSA (4/25, 16.0\%). The prevailing MRSA isolates were Taiwan related strains ST59-SCCmec-IVa/V (5/12, 41.6\%), most of them were found among children older than 2 years $(4 / 5,80.0 \%)$. The Berlin strains ST45-SCCmec-IVa/V (2/12, 16.7\%) were found in 2 infants aged 3 months. In the ST59-SCCmec-IV/IVa/ V-t437 clone, the antibiotic resistant profile was erythromycin/clindamycin /tetracycline. Moreover, the ST59-SCCmec-IV/V-t437 clone showed high resistance to erythromycin, clindamycin, and tetracycline, which was $88.9,88.9$, and $44.5 \%$, respectively. Additionally, ST59 was the most frequent ST in $p v l$ positive isolates, including 2 SCCmec type IV, 2 SCCmec type IVa, and 2 SCCmec type V. Other STs found in $p v l$ positive isolates included ST30 (3 MSSA, 1 MRSA), ST45 (2 MSSA, 2 MRSA), and ST59 MSSA (4 isolates). Figure 1 showed the $p v l$ gene distribution among the CC30, CC45 and CC59 strains, with a high proportion of $p v l$ gene distribution in CC59 strains. 
Table 3 Antimicrobial susceptibilities of Staphylococcus aureus isolated from children with AOM

\begin{tabular}{|c|c|c|c|c|}
\hline \multirow[t]{2}{*}{ Antibiotic } & \multicolumn{3}{|c|}{ Susceptibilities rate (\%) } & \multirow{2}{*}{$\begin{array}{l}P \\
\text { value }\end{array}$} \\
\hline & Overall $(n=37)$ & MSSA $(n=25)$ & $\operatorname{MRSA}(n=12)$ & \\
\hline Penicillin & $4(10.8)$ & $4(16.0)$ & $0(0.0)$ & 0.282 \\
\hline Gentamicin & $35(94.6)$ & $23(92.0)$ & $12(100.0)$ & 1.000 \\
\hline Erythromycin & $14(37.8)$ & $12(48.0)$ & $2(16.7)$ & 0.066 \\
\hline Tetracycline & $23(62.2)$ & $16(64.0)$ & $7(58.3)$ & 0.739 \\
\hline Ciprofloxacin & $37(100.0)$ & $25(100.0)$ & $12(100.0)$ & 1.000 \\
\hline Clindamycin & $15(40.5)$ & $13(52.0)$ & $2(16.7)$ & 0.040 \\
\hline Sulfamethoxazole- trimethoprim & $36(97.3)$ & $24(96.0)$ & $12(100.0)$ & 1.000 \\
\hline Chloramphenicol & $36(97.3)$ & $25(100.0)$ & $11(91.7)$ & 1.000 \\
\hline Rifampicin & $37(100.0)$ & $25(100.0)$ & $12(100.0)$ & 1.000 \\
\hline Linezolid & $37(100.0)$ & $25(100.0)$ & $12(100.0)$ & 1.000 \\
\hline Vancomycin & $37(100.0)$ & $25(100.0)$ & $12(100.0)$ & 1.000 \\
\hline
\end{tabular}

\section{Discussion}

$\mathrm{AOM}$ is a disease with worldwide prevalence having broad disease burden and may require prolonged treatment courses because at least a third of children have two or more episodes of AOM (recurrent AOM) in the first three years of life [14]. Reliable epidemiological data on etiology and burden of AOM are important as the data help clinicians with the selection of appropriate empiric antibiotic therapy for pediatric AOM and for public health policy decision-making.

In this retrospective study, we found that S. pneumoniae and $S$. aureus were the most predominant etiologic agents causing $\mathrm{AOM}$, being isolated in 36.4 and $16.2 \%$ of the specimens of children with AOM, respectively. Most of the $S$. aureus was MDR and resistant to erythromycin, clindamycin and tetracycline. The first two antibiotics (erythromycin and clindamycin) were the most frequent medicines prescribed by Chinese pediatricians for infectious diseases [4]. Historically, the major bacteria responsible for most cases of AOM were S. pneumoniae and $H$. influenzae [15]. The etiology of the pathogenic bacteria does not appear to have changed significantly

Table 4 Prevalence of erythromycin resistant genes among Staphylococcus aureus isolated from children with AOM

\begin{tabular}{|c|c|c|c|c|}
\hline \multirow[t]{2}{*}{ Gene } & \multirow{2}{*}{$\begin{array}{l}\text { No. of } \\
\text { positive } \\
\text { isolates } \\
\text { (\%) }\end{array}$} & \multicolumn{2}{|c|}{ No. distributing in } & \multirow{2}{*}{$\begin{array}{l}P \\
\text { value }\end{array}$} \\
\hline & & MSSA $(n=25)$ & MRSA $(n=12)$ & \\
\hline ermA & $22(59.4)$ & $12(32.4)$ & $10(83.3)$ & 0.002 \\
\hline ermB & $3(8.1)$ & $1(2.7)$ & $2(16.7)$ & 0.144 \\
\hline ermC & $9(24.3)$ & $4(10.8)$ & $5(41.7)$ & 0.016 \\
\hline ermA+ermC & $8(16.3)$ & $4(10.8)$ & $4(33.3)$ & 0.067 \\
\hline ermA+ermB & $2(5.4)$ & $0(0.0)$ & $2(16.7)$ & 1.000 \\
\hline ermB+ermC & $1(2.7)$ & $0(0.0)$ & $1(8.3)$ & 1.000 \\
\hline ermA+ermB+ermC & $1(2.7)$ & $0(0.0)$ & $1(8.3)$ & 1.000 \\
\hline
\end{tabular}

over time. Since the prevalence and the main causal agents of AOM varied by geographic location, we observed a different epidemiology and etiology from previous studies $[1,3,5]$ which revealed that the most causal agents of AOM were S. pneumoniae and H. influenzae, but our study was in line with one study conducted in southern China which demonstrated that the major pathogens causing AOM were $S$. pneumoniae and $S$. aureus, which accounted for 47.2 and $18.5 \%$ of the specimens isolated from AOM patients, respectively [2]. It has been reported that in the era of universal pneumococcal conjugate vaccine (PCV) immunization, that $H$. influenzae may become the predominant pathogen of $\mathrm{AOM}$, suggesting that the introduction of $\mathrm{PCV} 7$ can change the relative prevalence of main causal agents [16]. The same result was observed in Saudi children, after the introduction of pneumococcal vaccines in the routine immunization schedule, $S$. aureus has become the most predominant contributor to AOM [17]. The determinants of why $S$. aureus has become the second most common causal agent of AOM in China is poorly understood. In China, as the $H$. influenza b vaccine and PCV were self-paid and did not enter into the Chinese Expanded Program on Immunizations (EPI), we didn't see the changes of pathogen patterns distributed in the AOM disease for the vaccination of $H$. influenza b vaccine and PCV. The low coverage of PCV7 and antibiotic overuse and abuse in China can partly explain this disparity [2]. In this region of the world, S. aureus should be considered and targeted with appropriate therapy if initial therapies targeting S. pneumoniae fail to lead to clinical improvement, especially if culture is not available.

Antibiotic resistance has become an important public health problem in mainland China. Restriction of $\beta$-lactam use in MRSA infections required use of other types of antibiotic options for treatment. However, 
Table 5 Molecular characteristics and antibiotic resistance profiles of Staphylococcus aureus isolated from children with AOM

\begin{tabular}{|c|c|c|}
\hline Variables & MRSA $(n=12)$ & MSSA $(n=25)$ \\
\hline SCCmec (n) & $\mathrm{IV}(5), \operatorname{IVa}(4), \mathrm{V}(3)$ & - \\
\hline $\operatorname{CCs}(n)$ & CC30(1),CC45(2),CC59(9) & CC30(6),CC188(1), CC45(5),CC59(7), CC88(1), CC942(2) \\
\hline $\mathrm{STs}(\mathrm{n})$ & ST30(1),ST45(2),ST59(9) & ST188(13),ST30(6), ST398(1),ST45(5), ST59(7), ST88(1),ST942(2) \\
\hline Spa (n) & t037(1),t0181(2),t3845(1),t437(8) & $\begin{array}{l}\text { t021(4),t037(5),t1081(1),t1445(32), t189(3),t2592(1),t3551(1), } \\
\text { t3590(1),t3736(1),t437(5),t571(1) }\end{array}$ \\
\hline$p v /(n)$ & 9 & 9 \\
\hline erm-resistant genes ( $n$ ) & ermA(10).ermC(5),ermB(2) & ermA(2).ermC(4),ermB(1) \\
\hline $\begin{array}{l}\text { Antibiotir resistance profiles } \\
\text { (n) }\end{array}$ & $\mathrm{P}(12), \mathrm{E}(10), \mathrm{DA}(10), \mathrm{Cl}(1), \mathrm{TE}(5)$ & $\mathrm{P}(21), \operatorname{SXT}(1), \mathrm{GN}(2), \mathrm{E}(13), \mathrm{DA}(12), \mathrm{TE}(9)$ \\
\hline MLSBi (n) & 3 & 4 \\
\hline
\end{tabular}

$P$ penicillin, E erythromycin, GN gentamicin, TE tetracycline, DA clindamycin, $C l$ chloramphenicol, SXT Sulfamethoxazole- trimethoprim

except for resistance to all kind of $\beta$-lactam antibiotics, the MRSA isolates found in our study developed a high resistant rate to non- $\beta$-lactam antibiotics, especially to erythromycin, clindamycin and tetracycline. We found that the resistance rate to clindamycin in MSSA is even higher than in MRSA isolates. It was reported that both erythromycin and clindamycin have been common prescribed antibiotics for S. aureus infection [18]. A high resistance rate was also reported in mainland China [19], which indicated that the high antibiotic resistance rate of $S$. aureus is a common public health problem in China and that the two antibiotics were not the priority options for the empiric antibiotic therapy in pediatric infections. It was previously reported that in the macrolide resistance isolates, there were 59.4, 24.3, and $21.6 \%$ of which carried ermA, ermC and both ermA and ermC gene, respectively. Our study was consistent with a previous report that showed that of resistant $S$. aureus isolates, $37.7 \%$ had ermA, $26.6 \%$ had erm $C$ and $18.6 \%$ had both ermA and ermC genes [20], but different from a study conducted in Turkey which showed that $50 \%$ of ermA positive isolates also carried the ermC gene [10].

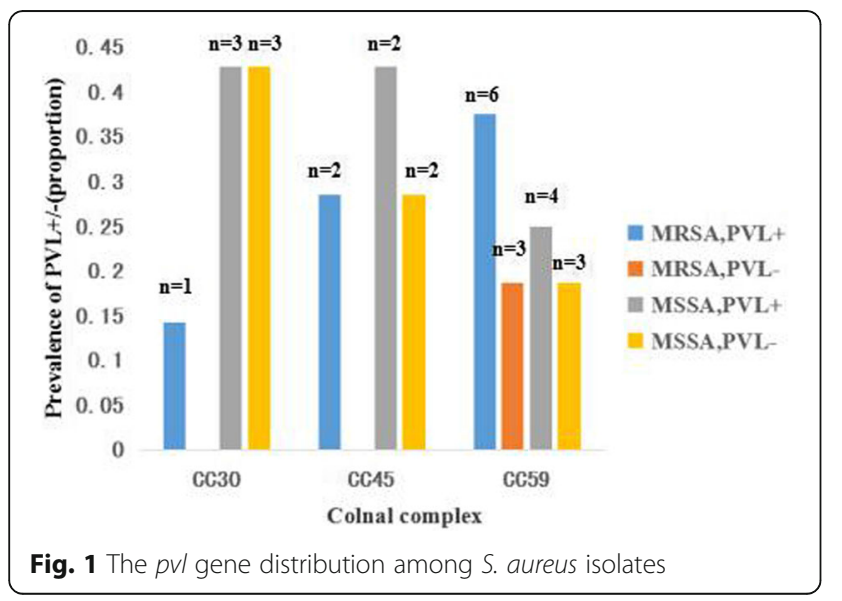

As a pathogen with extremely high prevalence, $S$. aureus causes various clinical infections such as skin and soft tissue infections (SSTIs) [19], invasive community-acquired MRSA (CA-MRSA) infections [21], and pneumonia [22]. Few studies about MRSA and MSSA isolates contemporaneously circulating among age-specific groups of children attending otolaryngology clinics have been examined [23, 24]. According to the previous report [11], hospital-acquired MRSA (HA-MRSA) is usually detected with SCCmec type I, II and III, while CA-MRSA is usually detected with SCCmec type IV, IVa and V. In this study, all of the MRSA isolates carried SCCmec IV, IVa and V, which confirmed that these MRSA isolates belonged to CA-MRSA. Twelve Spa types and seven ST types clustered into 7 clonal complex (CCs) among MSSA and 3 CCs among MRSA were observed in our study, indicating that there is great genetic diversity in $S$. aureus isolated from AOM patients. MSSA isolates with a genetic background (ST30-t037, ST45-t1081 and ST59-t437) was common to MRSA clones in this study suggesting that these MSSA isolates might have the potential to become CA-MRSA clones once acquisition of the mecA gene occurs [21].

Despite the high prevalence, only a few epidemic clones have been identified in China [25-27]. Previous studies throughout mainland China found that ST59$\mathrm{SCC} m e c-\mathrm{IVa} / \mathrm{V}$ strains were the most common strains causing CA-MRSA infections among children [25-28]. Our study also confirmed that the predominant sequence type of MRSA isolated from AOM children was ST59, which accounted for $75 \%$ of all the MRSA isolates. The previous report of ST59 was detected from a few MSSA isolates and in a single MRSA isolate in the United States, a large proportion of ST59 emerging in Taiwan was reported in 2004 and ST59-MRSA was called Taiwan clone [29]. ST59 was not only predominant in Shanghai [30], Guangzhou [31], and Taiwan [29], but also served as prevailing strains in Hongkong [32] 
and Vietnam [33]. The Asian Network for Surveillance of Resistant Pathogens (ANSORP) study conducted in 17 hospitals from Asian countries demonstrated that the predominant clones of CA-MRSA isolates were ST59-MRSA-SCCmec type IV-spa type t437 [34]. These findings suggested that ST59 is currently spreading between adjacent regions and supporting its dominance in the Asian region as a whole [33]. It is widely assumed that the CA-MSSA isolates acquiring the resistance gene $m e c A$ would become the major sources of CA-MRSA. In our study, we observed that ST59-MSSA was the predominant sequence type in the MSSA group, accounting for $28 \%$ of all MSSA isolates, which indicated that the $S$. aureus isolates undergoing genetic variations have great capacities for environmental adaption. The similar genetic background of ST59 between MRSA and MSSA isolates was also observed in ST30 and ST45 in our study.

ST45 was the second prevailing ST in our study, accounting for $20 \%$ of MSSA and $16.7 \%$ of MRSA isolates. It was reported that clonal complex 45 (CC45) is common throughout European countries such as Germany and the Netherlands and Belgium [35]. The ST45-SCCmec-IV/ $\mathrm{V}-\mathrm{t} 437$ clone is well known as the Berlin clone. The Berlin clone was first observed in 1993, and its emergence was attributed to acquisition of $m e c A$ by a community clone of MSSA [36]. The ST45 now spread in Hongkong [35] and mainland China [37], including in western China where our study was conducted. It was speculated that CC45 strains may be more transmissible among health care settings and hospitals [35].

One of the interesting findings was that ST398-MSSA was found in this study. ST398 is considered as a livestock-associated pathogen mainly affecting people in contact with major animal reservoirs [38]. It is noteworthy that this AOM case with isolates of ST398 reported no direct livestock-associated risk factors, although many reports documented that persons living in places of high livestock density were found to have a greater chance of livestock-associated CC398 carriage even if they lacked direct contact with animals $[39,40]$. CC398 may now be sporadic and distributed in China including areas such as Shanghai [30] and Liuzhou. This study finding suggests the probability of CC398 transmission via human contact instead of animal contact [41].

Panton-Valentine leukocidin (PVL) is a bicomponent toxin that can cause the lysis of leucocytes and it is a main virulence factor of $S$. aureus which is responsible for severe invasive disease such as necrotizing pneumonia [30]. An important finding in this study was the high detection rate of the $p v l$ gene in $S$. aureus isolates, with significant differences between the MRSA and the MSSA groups. Our result was consistent with previous reports indicating that the $p v l$ gene was more common in MRSA isolates than in MSSA isolates [42]. Several studies found that the proportion of $p v l$ positivity was approximately $27-40 \%$ among S.aureus isolates detected from children in mainland China [30]. In the current study, the pvl gene was found in ST30, ST45 and ST59 clones. It was reported that CA-MRSA ST59 isolates had significantly more pronounced virulence than the geographically matched HA-MRSA clones ST239 in various animal models, including the $p v l$ gene [43]. The CC59 was predominant among $p v l$ positive CA-MRSA in mainland China [30], for example, Li et al. [44] reported $55.5 \%$ of CC59 MRSA isolates to be $p v l$ positive in China, while we detected $66.7 \%$ of CC59 MRSA isolates with $p v l$ positive in AOM disease.

There are some limitations to our study. First of all, the single-center design and the small number of AOM patients may limit the generalizability of our study results. Secondly, the AOM cases in this study may not accurately represent all AOM cases as we swabbed spontaneous ear pus drainage from the deep ear canal and the external auditory canal to culture organisms, the results of which may or may not have included the true middle ear pathogen. S.aureus may have been a leading cause of AOM, but as we swabbed the ear canal, this may lead to detection of some colonizing agents such as S.aureus. Lastly, a retrospective review of medical records for identifying patients presented to an Otolaryngology clinic may have potentially decreased the generalizability of the results, as some children may have had more severe disease which were referred to a surgeon, as opposed to a primary care provider.

\section{Conclusion}

In conclusion, $S$. aureus was a leading cause for AOM in children in Liuzhou. Most of the S. aureus was MDR and carried high proportion of ermA and ermC gene. CA-MRSA (ST59-SCCmec-IV/V-t437) is circulating in children with AOM, suggesting a potential for CA-MRSA transmission from community to hospital. These findings support growing concern about continued surveillance of $S$. aureus infections in both communities and hospitals, and raise questions about the routine antibiotic use for the treatment of $S$. aureus infections in China and in countries worldwide.

\footnotetext{
Abbreviations

ANSORP: Asian Network for Surveillance of Resistant Pathogens; AOM: Acute otitis media; CA-MRSA: Community-acquired MRSA; CCs: Clonal complexs; CLSI: Clinical and Laboratory Standards Institute; EPI: Expanded Program on Immunization; H. influenzae: Haemophilus influenzae; HA-MRSA: hospitalacquired MRSA; M. catarrhalis: Moraxella catarrhalis; MDR: Multi-drug resistant; MICs: Minimum inhibitory concentrations; MLST: Multilocus Sequence Typing; MRSA: Methicillin- resistant S.aureus; MSSA: Methicillin-susceptible S.aureus; PCV: Pneumococcal conjugate vaccine; pvl: Panton-Valentine Leukocidin; S. pneumoniae: Streptococcus pneumoniae; S.aureus: Staphylococcus aureus; SCCmec: Staphylococcal cassette chromosome mec; SSTIs: Skin and soft tissue infections; STs: Sequence types
} 


\section{Acknowledgements}

Not applicable.

\section{Funding}

This manuscript was funded by Guangxi Natural Science Foundation (No. 2015GXNSFBA139129) and Guangxi Medical and Health Self-funding Project (No Z20170509 and No Z20180022). The funders had no role in study design, data collection and analysis, decision to publish, or preparation of the manuscript.

\section{Availability of data and materials}

We declare that the data supporting the conclusions of this article are fully described within the article, and the database is available from the first author (1365191235@qq.com) upon reasonable request.

\section{Authors' contributions}

J C and J F designed the study and drafted an outline. S M and J F participated in data analysis, J F draft of initial manuscript, N L, S X and P Q participated in diagnosing AOM and collected the data, E M critically reviewed and revised the manuscript and all of authors approved the final content off this manuscript.

\section{Ethics approval and consent to participate}

This study was approved by the Institutional Review Board of Liuzhou Maternity and Child Healthcare Hospital.

\section{Consent for publication}

Not applicable.

\section{Competing interests}

The authors declare that they have no competing interests.

\section{Publisher's Note}

Springer Nature remains neutral with regard to jurisdictional claims in published maps and institutional affiliations.

\section{Author details}

'Department of Laboratory, Liuzhou Maternity and Child Healthcare Hospital, Liuzhou 545001, China. ${ }^{2}$ Department of Neonatology, Liuzhou Maternity and Child Health Care Hospital, Liuzhou 545001, China. ${ }^{3}$ Department of Otolaryngology, Liuzhou Maternity and Child Health Care Hospital, Liuzhou 545001, Guangxi, China. ${ }^{4}$ Children's Hospital of Michigan, Detroit, MI, USA. ${ }^{5}$ Department of Pediatrics, Wayne State University School of Medicine, 3901 Beaubien Blvd, Detroit, Ml 48201, USA.

Received: 26 June 2018 Accepted: 5 December 2018 Published online: 15 December 2018

\section{References}

1. Vergison A, Dagan R, Arguedas A, Bonhoeffer J, Cohen R, Dhooge I, et al. Otitis media and its consequences: beyond the earache. Lancet Infect Dis. 2010;10(3):195-203.

2. Ding $Y$, Geng $Q$, Tao Y, Lin Y, Wang Y, Black S, et al. Etiology and epidemiology of children with acute otitis media and spontaneous otorrhea in Suzhou, China. Pediatr Infect Dis J. 2015;34(5):e102-6.

3. Chen YJ, Hsieh YC, Huang YC, Chiu CH. Clinical manifestations and microbiology of acute otitis media with spontaneous otorrhea in children. J Microbiol Immunol Infect. 2013 Oct;46(5):382-8.

4. Yao KH, Yang YH. Streptococcus pneumoniae diseases in Chinese children: past, present and future. Vaccine. 2008 Aug 18;26(35):4425-33.

5. Casey JR, Pichichero ME. Changes in frequency and pathogens causing acute otitis media in 1995-2003. Pediatr Infect Dis J. 2004 Sep;23(9):824-8.

6. Moran GJ, Krishnadasan A, Gorwitz RJ, Fosheim GE, McDougal LK, Carey RB, et al. EMERGEncy ID net study group. Methicillin-resistant $S$. aureus infections among patients in the emergency department. N Engl J Med. 2006;355(7):666-74.

7. Maree CL, Daum RS, Boyle-Vavra S, Matayoshi K, Miller LG. Communityassociated methicillin-resistant Staphylococcus aureus isolates causing healthcare-associated infections. Emerg Infect Dis. 2007;13(2):236-42.
8. Clinical Laboratory Standards Institute 2016. Performance standards for antimicrobial susceptibility testing; 26th informational supplement. Wayne: CLSI document M100-S23 Clinical Laboratory Standards Institute.

9. McClure JA, Conly JM, Lau V, Elsayed S, Louie T, Hutchins W, et al. Novel multiplex PCR assay for detection of the staphylococcal virulence marker Panton-valentine leukocidin genes and simultaneous discrimination of methicillin-susceptible from -resistant staphylococci. J Clin Microbiol. 2006; 44(3):1141-4.

10. Yıldız Ö, Çoban AY, Şener AG, Coşkuner SA, Bayramoğlu G, Güdücüoğlu $H$, et al. Antimicrobial susceptibility and resistance mechanisms of methicillin resistant Staphylococcus aureus isolated from 12 hospitals in Turkey. Ann Clin Microbiol Antimicrob. 2014;13:44.

11. Zhang K, McClure JA, Conly JM. Enhanced multiplex PCR assay for typing of staphylococcal cassette chromosome mec types I to $\mathrm{V}$ in methicillinresistant Staphylococcus aureus. Mol Cell Probes. 2012;26(5):218-21.

12. Enright MC, Day NP, Davies CE, Peacock SJ, Spratt BG. Multilocus sequence typing for characterization of methicillin-resistant and methicillin-susceptible clones of Staphylococcus aureus. J Clin Microbiol. 2000;38(3):1008-15.

13. Harmsen D, Claus H, Witte W, Rothgänger J, Claus H, Turnwald D, et al. Typing of methicillin-resistant Staphylococcus aureus in a university hospital setting by using novel software for spa repeat determination and database management. J Clin Microbiol. 2003;41(12):5442-8.

14. Marchisio P, Nazzari E, Torretta S, Esposito S, Principi N. Medical prevention of recurrent acute otitis media: an updated overview. Expert Rev Anti-Infect Ther. 2014;12(5):611-20.

15. Sierra A, Lopez P, Zapata MA, Vanegas B, Castrejon MM, Deantonio R, et al. Non-typeable Haemophilus influenzae and Streptococcus pneumoniae as primary causes of acute otitis media in colombian children: a prospective study. BMC Infect Dis. 2011;11:4.

16. Leibovitz E, Jacobs MR, Dagan R. Haemophilus influenzae: a significant pathogen in acute otitis media. Pediatr Infect Dis J. 2004;23:1142-52.

17. Al-Mazrou KA, Shibl AM, Kandeil W, Pirçon JY, Marano C. A prospective, observational, epidemiological evaluation of the aetiology and antimicrobial susceptibility of acute otitis media in Saudi children younger than 5years of age. J Epidemiol Glob Health. 2014 Sep;4(3):231-8.

18. Changchien $\mathrm{CH}$, Chen YY, Chen SW, Chen WL, Tsay JG, Chu C. Retrospective study of necrotizing fasciitis and characterization of its associated methicillinresistant Staphylococcus aureus in Taiwan. BMC Infect Dis. 2011;11:297.

19. Rodriguez M, Hogan PG, Burnham CA, Fritz SA. Molecular epidemiology of Staphylococcus aureus in households of children with community-associated S aureus skin and soft tissue infections. J Pediatr. 2014 Jan;164(1):105-11.

20. Gul HC, Kilic A, Guclu AU, Bedir O, Orhon M, Basustaoglu AC. Macrolidelincosamide-streptogramin B resistant phenotypes and genotypes for methicillin-resistant Staphylococcus aureus in Turkey, from 2003 to 2006. Pol J Microbiol. 2008:57(4):307-12.

21. Qiao Y, Ning X, Chen Q, Zhao R, Song W, Zheng Y, et al. Clinical and molecular characteristics of invasive community-acquired Staphylococcus aureus infections in Chinese children. BMC Infect Dis. 2014;14:582.

22. Defres $S$, Marwick C, Nathwani D. MRSA as a cause of lung infection including airway infection, community-acquired pneumonia and hospitalacquired pneumonia. Eur Respir J. 2009;34(6):1470-6.

23. Kim SH, Kim MG, Kim SS, Cha SH, Yeo SG. Change in detection rate of methicillin-resistant Staphylococcus aureus and Pseudomonas aeruginosa and their antibiotic sensitivities in patients with chronic Suppurative otitis media. J Int Adv Otol. 2015;11(2):151-6.

24. Rath S, Das SR, Padhy RN. Surveillance of bacteria Pseudomonas aeruginosa and MRSA associated with chronic suppurative otitis media. Braz J Otorhinolaryngol. 2017;83(2):201-6.

25. Geng W, Yang Y, Wang C, Deng L, Zheng Y, Shen X. Skin and soft tissue infections caused by community-associated methicillin-resistant staphylococcus aureus among children in China. Acta Paediatr. 2010 Apr;99(4):575-80.

26. Geng W, Yang Y, Wu D, Huang G, Wang C, Deng L, et al. Molecular characteristics of community-acquired, methicillin-resistant Staphylococcus aureus isolated from Chinese children. FEMS Immunol Med Microbiol. 2010; 58(3):356-62.

27. Zhang W, Shen X, Zhang H, Wang C, Deng Q, Liu L, et al. Molecular epidemiological analysis of methicillin-resistant Staphylococcus aureus isolates from Chinese pediatric patients. Eur J Clin Microbiol Infect Dis. 2009;28(7):861-4.

28. Geng W, Yang Y, Wu D, Zhang W, Wang C, Shang Y, et al. Community-acquired, methicillin-resistant Staphylococcus aureus isolated from children with community-onset pneumonia in China. Pediatr Pulmonol. 2010;45(4):387-94. 
29. Wang CC, Lo WT, Chu ML, Siu LK. Epidemiological typing of communityacquired methicillin-resistant Staphylococcus aureus isolates from children in Taiwan. Clin Infect Dis. 2004;39(4):481-7.

30. Song Z, Gu FF, Guo XK, Ni YX, He P, Han LZ. Antimicrobial resistance and molecular characterization of Staphylococcus aureus causing childhood pneumonia in Shanghai. Front Microbiol. 2017;8:455.

31. Liu Y, Wang H, Du N, Shen E, Chen H, Niu J, et al. Molecular evidence for spread of two major methicillin-resistant Staphylococcus aureus clones with a unique geographic distribution in Chinese hospitals. Antimicrob Agents Chemother. 2009;53(2):512-8.

32. Ho PL, Chuang SK, Choi YF, Lee RA, Lit AC, Ng TK, et al. Hong Kong CAMRSA surveillance network. Community-associated methicillin-resistant and methicillin-sensitive Staphylococcus aureus: skin and soft tissue infections in Hong Kong. Diagn Microbiol Infect Dis. 2008;61(3):245-50.

33. Vu BN, Jafari AJ, Aardema M, Tran HK, Nguyen DN, Dao TT, et al. Population structure of colonizing and invasive Staphylococcus aureus strains in northern Vietnam. J Med Microbiol. 2016;65(4):298-305.

34. Song JH, Hsueh PR, Chung DR, Ko KS, Kang Cl, Peck KR, et al. ANSORP study group. Spread of methicillin-resistant Staphylococcus aureus between the community and the hospitals in Asian countries: an ANSORP study. J Antimicrob Chemother. 2011;66(5):1061-9.

35. Ho PL, Chow KH, Lo PY, Lee KF, Lai EL. Changes in the epidemiology of methicillin-resistant Staphylococcus aureus associated with spread of the ST45 lineage in Hong Kong. Diagn Microbiol Infect Dis. 2009;64(2):131-7.

36. Witte W. Antibiotic resistance in gram-positive bacteria: epidemiological aspects. J Antimicrob Chemother. 1999:44:1-9.

37. Wang L, Liu Y, Yang Y, Huang G, Wang C, Deng L, et al. Multidrug-resistant clones of community-associated meticillin-resistant Staphylococcus aureus isolated from Chinese children and the resistance genes to clindamycin and mupirocin. J Med Microbiol. 2012;61(9):1240-7.

38. Reynaga E, Navarro M, Vilamala A, Roure P, Quintana M, Garcia-Nuñez M, et al. Prevalence of colonization by methicillin-resistant Staphylococcus aureus ST398 in pigs and pig farm workers in an area of Catalonia Spain. BMC Infect Dis. 2016;16(1):716

39. Feingold BJ, Silbergeld EK, Curriero FC, van Cleef BA, Heck ME, Kluytmans JA. Livestock density as risk factor for livestock-associated methicillinresistant Staphylococcus aureus, the Netherlands. Emerg Infect Dis. 2012 18(11):1841-9.

40. Kuehn B. MRSA may move from livestock to humans. JAMA. 2012;308(17):1726.

41. Ye X, Fan Y, Wang X, Liu W, Yu H, Zhou J, et al. Livestock-associated methicillin and multidrug resistant $\mathrm{S}$. aureus in humans is associated with occupational pig contact, not pet contact. Sci Rep. 2016;6:19184.

42. Kuehnert MJ, Kruszon-Moran D, Hill HA, McQuillan G, McAllister SK, Fosheim $\mathrm{G}$, et al. Prevalence of Staphylococcus aureus nasal colonization in the United States, 2001-2002. J Infect Dis. 2006;193(2):172-9.

43. Li M, Dai Y, Zhu Y, Fu CL, Tan VY, Wang Y, et al. Virulence determinants associated with the Asian community-associated methicillin-resistant Staphylococcus aureus lineage ST59. Sci Rep. 2016:6:27899.

44. Li J, Wang L, Ip M, Sun M, Sun J, Huang G, et al. Molecular and clinical characteristics of clonal complex 59 methicillin-resistant Staphylococcus aureus infections in mainland China. PLoS One. 2013;8(8):e70602.

Ready to submit your research? Choose BMC and benefit from:

- fast, convenient online submission

- thorough peer review by experienced researchers in your field

- rapid publication on acceptance

- support for research data, including large and complex data types

- gold Open Access which fosters wider collaboration and increased citations

- maximum visibility for your research: over $100 \mathrm{M}$ website views per year

At BMC, research is always in progress.

Learn more biomedcentral.com/submissions 